
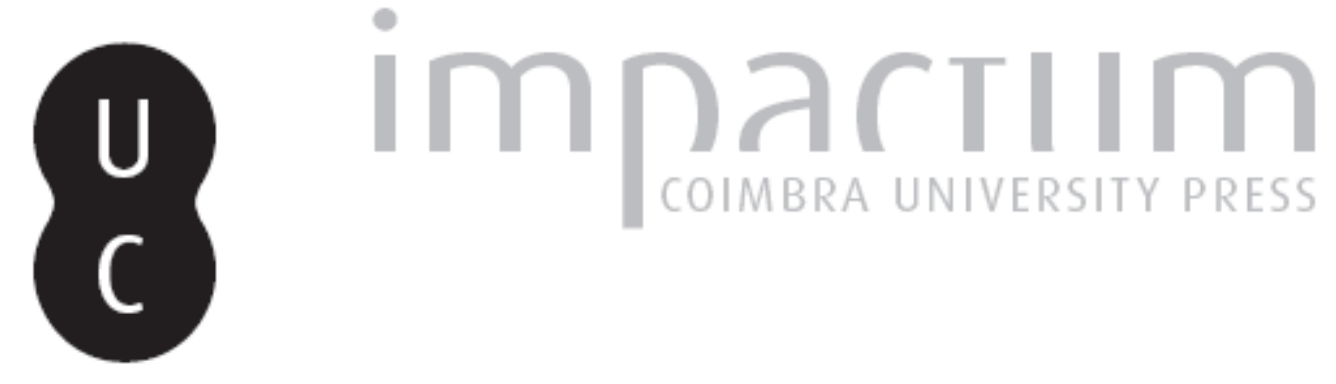

\title{
Legislação da União Europeia para o envelhecimento
}

\section{Autor(es): $\quad$ Veiga, Márcia}

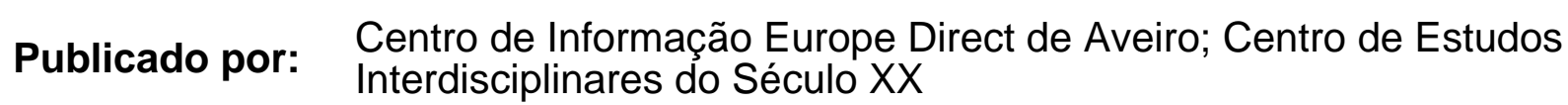

URL

persistente:

URI:http://hdl.handle.net/10316.2/33990

DOI:

DOI:http://dx.doi.org/10.14195/1647-6336_11_19

Accessed : $\quad$ 26-Apr-2023 07:28:14

A navegação consulta e descarregamento dos títulos inseridos nas Bibliotecas Digitais UC Digitalis, UC Pombalina e UC Impactum, pressupõem a aceitação plena e sem reservas dos Termos e Condições de Uso destas Bibliotecas Digitais, disponíveis em https://digitalis.uc.pt/pt-pt/termos.

Conforme exposto nos referidos Termos e Condições de Uso, o descarregamento de títulos de acesso restrito requer uma licença válida de autorização devendo o utilizador aceder ao(s) documento(s) a partir de um endereço de IP da instituição detentora da supramencionada licença.

Ao utilizador é apenas permitido o descarregamento para uso pessoal, pelo que o emprego do(s) título(s) descarregado(s) para outro fim, designadamente comercial, carece de autorização do respetivo autor ou editor da obra.

Na medida em que todas as obras da UC Digitalis se encontram protegidas pelo Código do Direito de Autor e Direitos Conexos e demais legislação aplicável, toda a cópia, parcial ou total, deste documento, nos casos em que é legalmente admitida, deverá conter ou fazer-se acompanhar por este aviso.

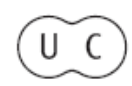


DEBATER

A EUROPA

jul-dez 2014

QUE EUROPA(S)?

CONTEXTOS E DESAFIOS 


\title{
Legislação da União Europeia para o Envelhecimento
}

\author{
Márcia Veiga \\ Doutoranda do Curso de Doutoramento \\ Estudos Contemporâneos pelo CEIS20/iii/UC \\ E-mail: marciarmveiga@gmail.com
}

\section{Resumo}

Este artigo tem por objetivo conhecer a política europeia para o envelhecimento. Optouse por uma análise com base na consulta à legislação da União Europeia através da Base EUR-Lex a partir dos seguintes descritores: "envelhecimento", "velhice", "velhos", “idosos”, “idades” e "gerações”. Foram analisados os regulamentos, diretivas, decisões, recomendações e pareceres da UE sobre o envelhecimento. Teve-se acesso, também, às comunicações e resoluções sobre esta temática, além do "Tratado" e da "Carta dos Direitos Fundamentais da UE”. Embora a legislação comunitária sobre esta matéria não seja de todo incisiva, percebe-se a importância que este debate tem alcançado no âmbito da União Europeia, o que é possível evidenciar através do avanço e do aprofundamento em torno das questões da velhice e do envelhecimento.

Palavras-chave: Envelhecimento; Velhice; Legislação; Políticas Públicas; União Europeia

\begin{abstract}
This article aims to identify the European policy for aging. Our analysis was based on the EU legislation retrieved through the EUR-Lex Database, using the following keyword descriptors: "aging", "old age", "old people", "senior citizens", "ages" and "generations". EU regulations, directives, decisions, recommendations, communications, resolutions and opinions on aging as well as the "European Treaty" and the "Charter of Fundamental Rights of the EU" were examined. Although the European legislation on this matter is not all that incisive, the importance this debate has
\end{abstract}


reached within the European Union is evident by the advancing and deepening of the legislation around the issues of old age and aging.

Keywords: Aging; Old Age; Legislation; Public Policy; European Union.

\section{Introdução}

O envelhecimento populacional é uma realidade global. Na União Europeia o envelhecimento vem crescendo a passos acelerados, levando a uma importante proeção: em 2050 estima-se que o número de europeus com idade igual ou superior aos 60 anos chegue aos $34 \%$ da população. Mais relevante é pensar que desses, mais da metade terá 80 anos ou mais ${ }^{1}$. Ou seja, rapidamente os idosos vão deixando de ser uma minoria para se constituírem em uma parcela significativa da população.

Os motivos que alavancaram esse processo são, basicamente, dois: o aumento da esperança de vida e a diminuição nas taxas de desenvolvimento demográfico.

O aumento da esperança de vida deu-se, principalmente, pelos progressos da ciência na área da saúde e da salubridade, nomeadamente após a Segunda Guerra Mundial - mas com alguns avanços já evidenciados no final do século XVIII e no século XIX (WILSON, 2009). O recuo nas taxas de desenvolvimento demográfico, por sua vez, relaciona-se com as quedas nas taxas de fecundidade e, também, com os fluxos migratórios, neste caso, com as emigrações, que tendem, ao contrário das imigrações, a acelerar o processo de envelhecimento das populações (GASPAR, 2009).

Essa conjuntura, por si só, não é necessariamente assustadora ou calamitosa. Reflete, antes de qualquer coisa, avanços significativos em um mundo com recursos finitos e em processo de escassez em busca de sustentabilidade. Entretanto, suscita reflexões e transformações em muitas concepções cristalizadas sobre velhice, cultura e sociedade. Não é à toa, portanto, que a temática da velhice e do envelhecimento comece a figurar nas agendas políticas de todo o mundo e, notadamente, da Europa, sendo colocada como importante pauta que requer, além de frequentes e sistemáticas discussões e reflexões, planos de ações comprometidos com a ideia de uma nova sociedade, em constantes transformações.

\footnotetext{
${ }^{1}$ Fonte: Organização das Nações Unidas - ONU, http://undesadspd.org/Ageing.aspx, [Acesso em 09/01/2014].
} 
Conhecer a política europeia para o envelhecimento e, consequentemente, as concepções de velhice e envelhecimento que perpassam essas diretrizes, é o objetivo deste trabalho.

Para atingir tal objetivo, a fonte utilizada foi a legislação comunitária para o envelhecimento, consultada através da base EUR-Lex ${ }^{2}$, e o "Jornal Oficial da União Europeia", a partir dos seguintes descritores: "envelhecimento", "velhice", "velhos", "idosos", "idades" e "gerações". Assim, foram consultados os regulamentos, as diretivas, as decisões e as recomendações e pareceres da UE sobre o envelhecimento. Além disso, teve-se acesso às comunicações e resoluções sobre esta temática, além do Tratado da União Europeia e da Carta dos Direitos Fundamentais da União Europeia.

\section{Legislação da União Europeia - Estrutura}

A União Europeia é uma organização política e econômica que congrega, até o momento, 28 países europeus ${ }^{3}$. Embora a ideia de Europa tenha se iniciado, ainda, no século XIV, foi a partir do final da Segunda Guerra Mundial - com suas consequências e novas configurações, que essa ideia foi evoluindo e se solidificando (MARTINS DA SILVA, 2010). Situada entre o sistema federal rígido, semelhante ao dos Estados Unidos, e o sistema flexível de cooperação intergovernamental, comparável ao das Nações Unidas, a União Europeia possui um caráter inédito, onde a soberania e independência de seus Estados-Membros foram garantidas, embora uma parte dessa "soberania" tenha sido congregada aos demais Estados-Membros, a fim de fortalecer a comunidade e os benefícios adivindos dessa unidade. Assim, foram criadas instituições comuns às quais foram delegados poderes decisórios, de modo a assegurar que as deliberações sobre assuntos do interesse comum pudessem ser feitas de forma democrática.

A União Europeia é uma comunidade de Direito e para o Direito. Assim, a instância legislativa tem grande importância em sua composição. Existem vários tipos de atos jurídico-legislativos, aplicados de diferentes formas, como: regulamentos, diretivas, decisões, recomendações e pareceres.

\footnotetext{
${ }^{2}$ Disponível em: http://eur-lex.europa.eu/pt/index.htm, [Acesso em: 16/01/2014].

${ }^{3}$ Com a entrada da Croácia, em 2013. Os demais países são: Alemanha, Áustria, Bélgica, Bulgária, Chipre, Dinamarca, Eslováquia, Eslovênia, Espanha, Estônia, Finlândia, França, Grécia, Hungria, Irlanda, Itália, Letônia, Lituânia, Luxemburgo, Malta, Países Baixos, Polônia, Portugal, Reino Unido, República Tcheca, Romênia e Suécia. Disponível em: http://europa.eu/about-eu/countries/index_pt.htm, [Acesso em: $13 / 01 / 2014]$.
} 
Toda a legislação europeia assenta-se em uma "base jurídica" que determina o procedimento legislativo a seguir. Esta "base jurídica" está ancorada nos dois tratados que estabelecem os objetivos da UE, as regras de funcionamento das suas instituições, o processo de tomada de decisões e a relação entre a União e os seus Estados-Membros: o Tratado da União Europeia e o Tratado sobre o Funcionamento da União Europeia. Ambos se assentam no caráter "cultural, religioso e humanista da Europa" e aos "princípios da liberdade, da democracia, do respeito pelos direitos do Homem e liberdades fundamentais e do Estado de direito" ". Dessa forma, a legislação comunitária é adotada pelas instituições e aplicada aos países da UE sob o abrigo dos tratados, que são acordos vinculativos entre os Estados-Membros. A grande maioria da legislação da UE é adotada através de um "processo legislativo ordinário", onde o poder legislativo é compartilhado pelo Parlamento e pelo Conselho.

\section{Legislação da União Europeia para o Envelhecimento}

Conforme explicitado na seção anterior, para este trabalho foi dada atenção aos atos legislativos explicitados através de regulamentos, diretrizes, decisões e recomendações e pareceres. Além disso, as comunicações e resoluções envolvendo a temática também foram revisadas. Ficaram de fora os acórdãos e decisões judiciais e as perguntas encaminhadas ao Parlamento Europeu. Estes documentos também se encontram disponíveis na base EUR-Lex, onde a pesquisa foi realizada.

Ao todo, foram analisados cinquenta e sete atos legislativos, assim distribuídos: vinte e três Pareceres, sendo quinze do "Comitê Econômico e Social", sete do "Comitê das Regiões" e um do "Parlamento Europeu"; doze Comunicações; oito Decisões e uma Proposta de Decisão; dez Resoluções; duas Recomendações e um Regulamento. As datas vão desde 1973, quando da Decisão $\mathrm{n}^{\circ} 79$, respeitante à totalização dos períodos de seguro e dos períodos equiparados em matéria de seguro de invalidez, velhice e morte, que garantia o pagamento de pensões aos segurados com menos de doze meses de contribuição, mas que tivessem completado o período mínimo estipulado pelo respectivo Estado-Membro; até 2013, com o Regulamento No 1381/2013 do Parlamento Europeu e do Conselho, de 17 de dezembro de 2013, que, embora não legisle

\footnotetext{
4 "Tratado da União Europeia" - versão consolidada, com as alterações introduzidas pelo "Tratado de Lisboa", assinado a 13 de dezembro de 2007 em Lisboa e em vigor desde 1 de dezembro de 2009. Publicado no Jornal Oficial da União Europeia em 26/10/2012. Disponível em: http://europa.eu/eulaw/treaties/index_pt.htm, [Acesso em: 10/01/2014].
} 
exatamente sobre o envelhecimento, cria o Programa "Direitos, Igualdade e Cidadania" para o período de 2014 a 2020, que prevê o combate à discriminação em razão do sexo, raça ou origem étnica, religião ou crença, deficiência, idade ou orientação sexual, e expressa a não-discriminação como um princípio fundamental da União, expresso, também, na "Carta dos Direitos Fundamentais da União Europeia", que, em seu artigo $21^{\circ}$, item 1 , deixa claro:

É proibida a discriminação em razão, designadamente, do sexo, raça, cor ou origem étnica ou social, características genéticas, língua, religião ou convicções, opiniões políticas ou outras, pertença a uma minoria nacional, riqueza, nascimento, deficiência, idade ou orientação sexual. (CARTA DOS DIREITOS FUNDAMENTAIS DA UNIÃO EUROPEIA, Artigo $21^{\circ}$, item 1 - Grifos nossos) $)^{5}$.

A década de 1980 trouxe uma Recomendação do Conselho, relativa aos princípios de uma política comunitária para a idade da reforma ${ }^{6}$.

Pode-se observar que as discussões e atos legislativos sobre envelhecimento começaram a ganhar dimensão na década de 1990 (com uma proposta de Decisão -1990 - três Decisões - 1991/1992/1993 -, cinco Pareceres - 1990/1992/1992/1995/1999 -, três Resoluções - 1990/1992/1995 - e duas Comunicações - 1993/1999), mas se intensificaram sobremaneira década e meia seguinte.

Nesse sentido, um dos primeiros atos deu-se através de uma proposta de Decisão do Conselho, relativa a ações comunitárias em favor dos idosos, apresentada à Comissão em 06 de abril de 1990 e submetida ao parecer do Comitê Econômico e Social em 07 de maio de 1990. Essa iniciativa propunha que no período de 01 de janeiro de 1991 a 31 de dezembro de 1993 fossem desenvolvidas ações a nível comunitário a favor dos idosos, com os seguintes objetivos:

1. Contribuir para a definição de estratégias preventivas para fazer face aos desafios de ordem económica e social resultantes do envelhecimento da população; 2. Criar estratégias inovadoras de solidariedade entre gerações e de integração da população idosa, que envolvam todos os agentes económicos e sociais, quer no meio rural, quer urbano; 3. Desenvolver e salientar as potencialidades positivas da contribuição dos

\footnotetext{
5 “Jornal Oficial da União Europeia”, 30/03/2010. Disponível em: http://eur-lex.europa.eu/LexUriServ/LexUriServ.do?uri=OJ:C:2010:083:0389:0403:pt:PDF, [Acesso em: 10/01/20149].

6 “Jornal Oficial da União Europeia", 18/12/1982. Disponível em: http://eur-lex.europa.eu/LexUriServ/LexUriServ.do?uri=OJ:L:1982:357:0027:0028:IT:PDF, [Acesso em: 09/03/2014].
} 
cidadãos idosos para a Comunidade. (PROPOSTA DE DECISÃO DO CONSELHO RELATIVA A ACÇÕES COMUNITÁRIAS A FAVOR DOS IDOSOS, apresentada pela Comissão em 6 de Abril de 1990) ${ }^{7}$.

Em 04 de julho de 1990, o Comitê Econômico e Social acolhe favoravelmente a proposta, considerando-a como "a primeira iniciativa oficial comunitária, embora de limitado alcance, a ser tomada em favor das pessoas de mais idade" ${ }^{\text {. }}$.

No ano seguinte, em 17 de outubro de 1991, a Comissão das Comunidades Europeias decide pela criação de um "grupo de ligação das pessoas idosas". Este grupo seria o elo entre os idosos e a Comissão, atuando como consultor para assuntos respeitantes à proteção dos interesses da pessoa idosa. Seus membros seriam indicados pelas organizações das pessoas idosas estabelecidas nos Estados-Membros. As primeiras instituições convidadas a indicar membros para compor o grupo foram o "Comitê de Coordenação dos Trabalhadores Reformados da Conferedação Europeia dos Sindicatos", a "Federação Europeia para as Pessoas Idosas", o "Eurolink Age", a "Federação Internacional das Associações das Pessoas Idosas" e a "Plataforma Europeia das Organizações da Terceira Idade”. Esta Decisão, após as devidas alterações, realizadas através de Parecer do Parlamento Europeu, ganha status de Resolução em 13 de julho de $1992^{9}$.

Em 24 de junho de 1992 o Conselho estabelece, através de Decisão, as normas, os objetivos, as ações e ações coordenadas para a organização do "Ano Europeu dos Idosos e da Solidariedade entre Gerações", previsto para o ano seguinte. O financiamento do projeto se deu em três instâncias, com ações voluntárias, ações cofinanciadas pelo orçamento comunitário e ações totalmente financiadas pelo orçamento comunitário.

É importante lembrar que o ano de 1993 foi instituído como o "Ano Europeu dos Idosos e da Solidariedade entre Gerações" por sugestão da primeira proposta de Decisão

\footnotetext{
7 “Jornal Oficial da União Europeia”, 16/05/1990. Disponível em: http://eur-lex.europa.eu/LexUriServ/LexUriServ.do?uri=OJ:C:1990:120:0008:0009:PT:PDF, [Acesso em: 10/01/2014].

8 "Parecer do Comitê Econômico e Social sobre a comunicação sobre os idosos". "Jornal Oficial da União Europeia”, 10/09/1990. Disponível em:

http://eur-lex.europa.eu/LexUriServ/LexUriServ.do?uri=OJ:C:1990:225:0014:0016:PT:PDF, [Acesso em 10/01/2014].

${ }^{9}$ Resolução Legislativa que contém o parecer do Parlamento Europeu sobre a proposta da Comissão do Conselho de uma decisão relativa à organização do Ano Europeu dos Idosos e da Solidariedade entre as Gerações, 1993. Publicada no "Jornal Oficial da União Europeia", 13/07/2012. Disponível em: http://eurlex.europa.eu/LexUriServ/LexUriServ.do?uri=OJ:C:1992:176:0212:0263:PT:PDF, [Acesso em 04/03/2014].
} 
relativa a ações em favor da pessoa idosa, que teve parrecer favorável do Comitê Econômico e Social ${ }^{10}$. Ao seu encerramento, foi publicada uma Comunicação Declaração de Princípio - do Conselho da União Europeia e dos Ministros dos Assuntos Sociais cujo texto constata que a evolução demográfica, com o aumento significativo e constante da população idosa em todos os Estados-Membros, tem "efeitos econômicos, sociais, sanitários e orçamentais" ${ }^{\prime 1}$, mas, ao mesmo tempo, reconhece a vontade política dos Estados-Membros em encontrarem uma resposta satisfatória aos desafios socioeconômicos do envelhecimento populacional. Para isso, convida-os a elaborar políticas aos domínios de interesse dessa população específica. Anterior a essa Declaração, em 21 de setembro desse mesmo ano, foi publicada uma Decisão do Conselho, relativa a uma iniciativa comunitária no domínio da tecnologia para deficientes e idosos (Tide), chamada de "Fase Bridge". Esse documento, tendo por objetivo o estímulo à criação de um mercado interno europeu das tecnologias de reabilitação a fim de facilitar a integração socioeconômica dos deficientes e idosos, decidiu pela abertura de uma chamada pública para apresentação de propostas que contemplassem os seguintes objetivos: “compreensão, clarificação e adaptação das tecnologias para dar resposta às necessidades dos grupos de utentes; desenvolvimento de novas aplicações das tecnologias de reabilitação, tais como casas inteligentes para os idosos, aparelhos auditivos avançados, etc.; incentivo à inovação e à transferência de tecnologia nos domínios das tecnologias de reabilitação; aceleração do desenvolvimento de normas e padrões técnicos". ${ }^{12} \mathrm{O}$ financiamento às propostas era de 30.000 ecus ${ }^{13}$, podendo chegar a 35.000, e a seleção ficaria a cargo da Comissão, assistida por um comitê composto por representantes dos Estados-Membros e presidido pelo representante da Comissão. Foram selecionados 55 projetos para financiamento em um

\footnotetext{
10 "Parecer do Comitê Econômico e Social sobre a proposta de decisão do Conselho relativa à organização do Ano Europeu dos Idosos e da Solidariedade entre as Gerações, 1993". "Jornal Oficial da União Europeia", 06/07/1992. Disponível em http://eurlex.europa.eu/LexUriServ/LexUriServ.do?uri=OJ:C:1992:169:0049:0051:PT:PDF. [Acesso em 04/03/2014].

11 "Declaração de Princípio do Conselho da UE e dos Ministros dos Assuntos Sociais" em 06/12/1993, no momento de encerramento do "Ano Europeu dos Idosos e da Solidariedade entre Gerações", publicada no "Jornal Oficial da União Europeia", 21/12/1993. Disponível em:

http://eur-lex.europa.eu/LexUriServ/LexUriServ.do?uri=OJ:C:1993:343:0001:0003:PT:PDF, [Acesso em: $11 / 01 / 2014]$.

12 "Decisão do Conselho de 21 de Setembro de 1993, relativa a uma iniciativa comunitária no domínio da tecnologia para deficientes e idosos (Tide) (1993-1994)". Publicada no "Jornal Oficial da União Europeia", 25/09/1993. Disponível em:

http://eur-lex.europa.eu/LexUriServ/LexUriServ.do?uri=OJ:L:1993:240:0042:0046:PT:PDF, [Acesso em: $11 / 01 / 2014]$.

${ }^{13}$ Unidade monetária criada a partir da instauração, em 1979, de um Sistema Monetário Europeu. Antecedeu ao euro.
} 
período compreendido entre novembro de 1993 a abril de 1994, após convite à apresentação de propostas publicado no "Jornal Oficial da União Europeia" de 21 de abril de 1993.

Em 31 de maio de 1995, o Comitê Econômico e Social emite Parecer ${ }^{14}$ sobre a proposta de Decisão do Conselho relativa ao Apoio Comunitário a Ações em favor dos Idosos. Esse Parecer é importante, pois nele o Comitê chama a atenção para a necessidade de se favorecer a participação e a tomada de decisões dos idosos em matérias que lhes dizem respeito. Assim, sugere que seja elaborada uma "Carta Comunitária dos Direitos Fundamentais das Pessoas Idosas”, privilegiando os seguintes objetivos: formação e reciclagem dos trabalhadores idosos; planificação e preparação da reforma; livre circulação e transferência das pensões; rendimento decente; direito à reforma; redução nas tarifas de transporte público; solidariedade entre gerações; direito a cuidados de saúde adequados; habitat adaptado às condições e necessidades dos idosos; residências de acolhimento e ajuda domiciliária; proteção contra a violência; preocupação com as necessidades e desejos dos idosos migrantes, minorias étnicas, idosos do meio rural, mulheres idosas e idosos dependentes.

É também do ano de 1995 a Resolução legislativa sobre a proposta de decisão do Conselho relativa ao apoio comunitário a ações em favor dos idosos ${ }^{15}$

Passados quatro anos, em maio de 1999, a Comissão das Comunidades Europeias publica uma comunicação intitulada "Uma Europa para todas as idades Promover a prosperidade e a solidariedade entre as gerações"16. Nesse mesmo ano, em 16 de setembro de 1999, o Comitê das Regiões emite Parecer ${ }^{17}$ sobre o Ano Internacional dos Idosos - 1999 -, instituído pela Organização das Nações Unidas. Nesse documento, são expressos os principais desafios para uma política da terceira idade: aumento da esperança de vida com uma vida ativa; assistência suficiente; necessidades em matéria de habitação, habitat e transportes; aumento das possibilidades

\footnotetext{
14 "Parecer sobre a Proposta de Decisão do Conselho relativa ao Apoio Comunitário a Acções em favor dos Idosos". Publicado no "Jornal Oficial da União Europeia", 11/09/1995. Disponível em:

http://eur-lex.europa.eu/LexUriServ/LexUriServ.do?uri=OJ:C:1995:236:0046:0049:PT:PDF, [Acesso em: 11/01/2014].

"Jornal Oficial da União Europeia", 20/11/1995. Disponível em: http://eurlex.europa.eu/LexUriServ/LexUriServ.do?uri=OJ:C:1995:308:0019:0094:PT:PDF, [Acesso em 10/03/2014].

16 Disponível em: http://ec.europa.eu/employment_social/social_situation/docs/com221_pt.pdf, [ACESSO EM 10/03/2014].

17 "Parecer do Comité das Regiões" sobre a "1999 - Ano Internacional dos Idosos". Publicado no "Jornal Oficial da União Europeia". Disponível em:

http://eur-lex.europa.eu/LexUriServ/LexUriServ.do?uri=OJ:C:1999:374:0036:0040:PT:PDF, [Acesso em: $11 / 01 / 2014]$.
} 
de aprendizagem e de participação. Alerta para a importância das dimensões locais e regionais das políticas a partir de investigações sobre o envelhecimento das populações e propõe a elaboração de um manual de boas práticas, no qual se registrem as experiências entre as gerações e que poderia constituir umcontributo construtivo e duradouro a iniciativa da ONU.

Assim, a década de 1990 pode ser identificada como um marco para as discussões sobre o envelhecimento no seio da União Europeia. Muito ainda estava por vir, nos quase quinze anos seguintes, refletindo $\mathrm{o}$ amadurecimento $\mathrm{e} \quad \mathrm{o}$ redimensionamento das questões relativas ao envelhecimento e à velhice, propriamente dita.

Em 19 de outubro de 2000, o Comitê Econômico e Social elaborou um Parecer sobre os trabalhadores idosos. Esse Parecer analisava as transformações do trabalho nos ciclos de vida e fazia um importante alerta:

É necessária uma mudança de mentalidades e atitudes. Não basta proibir ofertas de emprego com limites de idade se as políticas de recrutamento não acompanharem o processo. A mudança de mentalidades não é obra de um só grupo: todos - poderes públicos, empregadores e trabalhadores e sociedade em geral - devem sentir-se directamente empenhados em fazer evoluir a situação (PARECER DO COMITÊ ECONÔMICO E SOCIAL SOBRE OS TRABALHADORES IDOSOS, Jornal Oficial da União Europeia, 16/01/2001, p. 54) ${ }^{18}$.

Nesse mesmo ano (17 de novembro de 2000), a Comissão encaminhou, ao Conselho, ao Parlamento e aos Comitês Econômico e Social e das Regiões, uma Comunicação relativa à avaliação da "Fase Bridge da Tide" (tecnologia para deficientes e idosos). Os cinquenta e cinco projetos foram analisados e avaliados por pelo menos três avaliadores independentes, de acordo com seus domínios de especialização. Além disso, foi aplicado um inquérito aos coordenadores dos projetos. A Comunicação avaliou de forma positiva essa fase da iniciativa fazendo as seguintes recomendações: a União Europeia deveria continuar a apoiar uma gama vasta e integrada de medidas destinadas a idosos e pessoas com deficiências; deveriam se realizar atividades de investigação e desenvolvimento tecnológico convincentes e com financiamento adequado para benefício dos idosos e das pessoas com deficiências, tanto no domínio

\footnotetext{
${ }^{18}$ Disponível em: http://eur-lex.europa.eu/LexUriServ/LexUriServ.do?uri=OJ:C:2001:014:0050:0062:PT:PDF, [Acesso em: $12 / 01 / 2014]$.
} 
das tecnologias da sociedade da informação como noutros domínios de investigação; as investigações e desenvolvimento tecnológico deveriam ser complementados com um forte enquadramento da política social da União Europeia.

Ainda em 2000, é aprovada, em 15 de dezembro, a Resolução do Parlamento Europeu sobre a Comunicação da Comissão "Uma Europa para todas as idades Promover a prosperidade e a solidariedade entre as gerações" ${ }^{\prime 1}$, que reitera que o processo de adequação da sociedade ao envelhecimento da população deve ser concebido como valorização do idoso e não como mera adaptação unilateral por parte deste às condições do mundo do trabalho.

No ano seguinte, em 13 de junho de 2001, o Comitê das Regiões elabora seu parecer $^{20}$ em relação ao relatório acima mencionado, encaminhado pela Comissão. O documento ratifica o relatório anterior, sublinhando a necessidade de se projetarem imóveis privados, além dos públicos - já sujeitos às normas legislativas -, acessíveis aos idosos e pessoas com deficiência.

É do mesmo ano, 2001, a Comunicação da Comissão ao Conselho, Parlamento e Comitês, relativa ao "Futuro dos cuidados de saúde e dos cuidados para as pessoas idosas: garantir a acessibilidade, a qualidade e a viabilidade financeira" ${ }^{21}$. No documento, de 23 páginas, são discutidos os desafios comuns aos Estados-Membros: impactos do envelhecimento demográfico nos sistemas e nas despesas; o desenvolvimento de novas tecnologias e terapêuticas; e a melhoria do bem-estar e do nível de vida; bem como a diversidade dos sistemas nacionais e a contribuição das políticas comunitárias a partir de três objetivos a longo prazo: acessibilidade, qualidade e viabilidade financeira.

Em 2002, a Comissão das Comunidades Europeias publica, em 05 de março, uma Comunicação intitulada "Resposta da Europa ao Envelhecimento da População Mundial - Promover o Progresso Económico e Social num Mundo em Envelhecimento - Contribuição da Comissão Europeia para a II Assembleia Mundial sobre o

\footnotetext{
19 "Jornal Oficial da União Europeia", 17/08/2001. Disponível em: http://eurlex.europa.eu/LexUriServ/LexUriServ.do?uri=OJ:C:2001:232:0381:0381:PT:PDF, [Acesso em 10/03/2014].

20 "Parecer do Comitê de Regiões" sobre a "Comunicação da Comissão ao Conselho, ao Parlamento Europeu, ao Comitê Econômico e Social e ao Comitê das Regiões - Avaliação da Fase Bridge da TIDE (Iniciativa no domínio da tecnologia para deficientes e idosos)". "Jornal Oficial da União Europeia", 14/12/2001. Disponível em: http://eur-lex.europa.eu/LexUriServ/LexUriServ.do?uri=OJ:C:2001:357:0024:0026:PT:PDF, [Acesso em: $12 / 01 / 2014]$.

${ }^{21}$ Disponível em: http://eur-lex.europa.eu/LexUriServ/LexUriServ.do?uri=COM:2001:0723:FIN:PT:PDF, [Acesso em: 12/01/2014].
} 
Envelhecimento [realizada em Madrid entre os dias 08 e 12 de abril daquele ano, sob organização da ONU]", em que manifesta apoio aos esforços para desenvolver uma posição comum entre os Estados-Membros nas questões realtivas ao envelhecimento e identifica o pioneirismo europeu "na definição de uma grande variedade de respostas institucionais ao problema do envelhecimento da população (reforma, sistemas de pensões, serviços de saúde especializados, prestação de cuidados em lares ou instituições, centros de actividades, etc.) ${ }^{\text {"22 }}$.

Em 03 de julho do mesmo ano, o Comitê das Regiões, através de Parecer sobre "Relatório da Comissão ao Conselho, ao Parlamento Europeu, ao Comité Económico e Social e ao Comité das Regiões" - relatório solicitado pelo Conselho Europeu de Estocolmo: “Aumentar os níveis de participação dos trabalhadores e promover o envelhecimento em actividade" 23 , recomenda que sejam observados os seguintes pontos: alargamento dos níveis de participação dos idosos na sociedade, não os associando, estritamente, ao mercado de trabalho; estímulo à aprendizagem ao longo da vida; solidariedade nos sistemas de cuidados de saúde; fomento da livre circulação de trabalhadores no mercado comunitário através do reconhecimento de diplomas e da supressão de discrepâncias socioeconômicas que dificultam a mobilidade; parceria entre as autarquias locais e regionais e a criação de "regiões de aprendizagem", onde ambas as autarquias podem se retroalimentar com as trocas de experiências.

No limiar do ano de 2003, no dia 03 de janeiro, a Comissão apresenta a seguinte Comunicação: "Cuidados de saúde e cuidados aos idosos: apoiar as estratégias nacionais destinadas a garantir um elevado nível de protecção social" ${ }^{24}$. Nesse mesmo ano, passado apenas um mês, no dia 06 de fevereiro, o Conselho publica a "Resolução do Conselho relativa à inclusão social — através do Diálogo Social e da Parceria”, onde coloca a necessidade "da garantia de um equilíbrio entre flexibilidade e segurança, por via da sua resposta a desafios como o desenvolvimento da aprendizagem ao longo da

\footnotetext{
${ }^{22}$ Disponível em: http://eur-lex.europa.eu/LexUriServ/LexUriServ.do?uri=COM:2002:0143:FIN:PT:PDF, [Acesso em: 12/01/2014].

${ }^{23}$ Publicado pelo "Jornal Oficial da União Europeia", 22/11/2002. Disponível em: http://eurlex.europa.eu/LexUriServ/LexUriServ.do?uri=OJ:C:2002:287:0001:0005:PT:PDF, [Acesso em: 12/01/2014].

${ }^{24}$ Disponível em: http://eur-lex.europa.eu/LexUriServ/LexUriServ.do?uri=COM:2002:0774:FIN:PT:PDF, [Acesso em: 12/01/20149.
} 
vida, o aumento da mobilidade e o envelhecimento activo e da promoção da igualdade de oportunidades e da diversidade" 25 .

Em 03 de março de 2004, a Comissão propõe, através de Comunicação ${ }^{26}$, o aumento dos níveis de emprego dos trabalhadores mais velhos e o retardamento da saída do mercado de trabalho. Sobre tal Comunicação, o Comitê das Regiões se pronuncia, através de Parecer (de 29/09/2004), alertando sobre a insuficiência de tais medidas "para valorizar as potencialidades da população mais velha, sendo necessário também o reconhecimento do significativo contributo das pessoas mais velhas para as actividades socialmente úteis, de tipo voluntário e informal; por conseguinte, é oportuno reconhecer a importância de todas as profissões, quer sejam de importância económica quer de importância social, para a economia, para o bem-estar individual e para a coesão social ao nível local”27. Essa matéria também é alvo de pronunciamento do Comitê Econômico Social, em Parecer de 15 de dezembro de 2004. Apesar de concordar com grande parte do teor da Comunicação, o Comitê ressalva que a formação, formação profissional e aprendizagem ao longo da vida não podem ser tratadas de forma isolada. A formação deve ter papel motivador para qualquer idade. Além disso, sugere que a vida ativa deva ser abandonada gradativamente, quando os trabalhadores assim o quiserem, e com a redução gradativa do tempo de trabalho, e não de forma abrupta, através de uma "data inexorável" 28 .

Ainda no ano de 2004, o Comitê Econômico e Social pronunciou-se outras duas vezes com relação à temática do envelhecimento. O primeiro desses dois pareceres foi elaborado em 15 de setembro e versava sobre as necessidades de investigação no

\footnotetext{
25 Publicado no "Jornal Oficial da União Europeia", 18/02/2003. Disponível em: http://eurlex.europa.eu/LexUriServ/LexUriServ.do?uri=OJ:C:2003:039:0001:0002:PT:PDF, [Acesso em: $12 / 01 / 2014]$.

26 "Comunicação da Comissão ao Conselho, ao Parlamento Europeu, ao Comité Económico e Social Europeu e ao Comité das Regiões: Aumentar os níveis de emprego dos trabalhadores mais velhos e retardar a saída do mercado de trabalho", disponível em: http://eurlex.europa.eu/LexUriServ/LexUriServ.do?uri=COM:2004:0146:FIN:PT:PDF, [Acesso em: 12/01/2014].

27 "Parecer do Comité das Regiões sobre a Comunicação da Comissão ao Conselho, ao Parlamento Europeu, ao Comité Económico e Social Europeu e ao Comité das Regiões - Aumentar os níveis de emprego dos trabalhadores mais velhos e retardar a saída do mercado do trabalho", publicado no "Jornal Oficial da União Europeia", 18/02/2005. Disponível em: http://eurlex.europa.eu/LexUriServ/LexUriServ.do?uri=OJ:C:2005:043:0007:0009:PT:PDF, [Acesso em: $12 / 01 / 2014]$.

${ }_{28}$ "Parecer do Comité Económico e Social sobre a Comunicação da Comissão ao Conselho, ao Parlamento Europeu, ao Comité Económico e Social Europeu e ao Comité das Regiões - Aumentar os níveis de emprego dos trabalhadores mais velhos e retardar a saída do mercado do trabalho", publicado no "Jornal Oficial da União Europeia", 28/06/20005. Disponível em: http://eurlex.europa.eu/LexUriServ/LexUriServ.do?uri=OJ:C:2005:157:0120:0129:PT:PDF, [Acesso em:
} 12/01/2014]. 
domínio das mutações demográficas para a qualidade de vida dos idosos e para as necessidades tecnológicas. Esse Parecer concluiu pela importância do incentivo ao desenvolvimento de pesquisas multi e interdisciplinares e da investigação geriátrica socialmente participativa, no sentido de que a velhice seja vista e considerada pela sociedade com mais dignidade ${ }^{29}$. O outro Parecer do Comitê Econômico e Social nesse ano foi elaborado em 16 de dezembro de $2004^{30}$ e refletia sobre as relações entre as gerações, consideradas, no próprio texto, como "um importante e vasto tema para reflexão sociológica e política”.

O ano de 2005 inicia (16/03/2005) com uma Comunicação da Comissão intitulada: "Livro Verde": "Uma nova solidariedade entre gerações face às mutações demográficas" ${ }^{\prime 1}$, que discorre sobre os desafios da demografia europeia e propõe uma nova solidariedade entre as gerações, a partir do apoio mútuo e de transferência de competências e experiências. Analisando essa Comunicação, o Comitê das Regiões apresenta um Parecer, em 17 de novembro, sugerindo um debate ao nível comunitário, nacional, regional e local sobre a evolução demográfica e suas respectivas consequências, buscando respostas às seguintes idagações: "como reforçar a solidariedade entre as gerações através de uma integração social mais forte dos jovens e dos reformados e idosos; como promover a qualidade de vida, um grau de saúde elevado para todos e a formação contínua, incluindo depois da reforma; como adaptar os sistemas de produção e de protecção social às exigências das sociedades em envelhecimento; como garantir que o envelhecimento seja tido em conta em todos os domínios de acção política?"32

\footnotetext{
29 "Parecer do Comité Económico e Social Europeu sobre Rumo ao $7^{\circ}$ programa-quadro em matéria de investigação: As necessidades de investigação no domínio das mutações demográficas - Qualidade de vida dos idosos e necessidades tecnológicas", publicado no "Jornal Oficial da União Europeia", 23/03/2005. Disponível em:

http://eur-lex.europa.eu/LexUriServ/LexUriServ.do?uri=OJ:C:2005:074:0044:0054:PT:PDF, [Acesso em: $12 / 01 / 2014]$.

${ }^{30}$ Publicado no "Jornal Oficial da União Europeia”, 28/06/2005. Disponível em:

http://eur-lex.europa.eu/LexUriServ/LexUriServ.do?uri=OJ:C:2005:157:0150:0154:PT:PDF, [Acesso em: $12 / 01 / 2014]$.

${ }^{31}$ Disponível em:

http://eur-lex.europa.eu/LexUriServ/LexUriServ.do?uri=COM:2005:0094:FIN:PT:PDF, [Acesso em: 14/01/2014].

${ }^{32}$ Parecer do Comité das Regiões sobre o Livro Verde "Uma nova solidariedade entre gerações face às mutações demográficas". Publicado no Jornal Oficial da União Europeia, 16/05/2006. Disponível em: http://eur-lex.europa.eu/LexUriServ/LexUriServ.do?uri=OJ:C:2006:115:0061:0064:PT:PDF, [Acesso em 14/01/2014].
} 
Em 23 de março de 2006 o Parlamento Europeu publica uma Resolução ${ }^{33}$ sobre os desafios demográficos e a solidariedade entre gerações, em que acolhe a Comunicação da Comissão intitulada "Livro Verde - Uma nova solidariedade entre gerações face às mutações demográficas" e, dentre outras considerações, advoga uma nova solidariedade entre gerações e um maior desenvolvimento dos modelos sociais existentes na União Europeia, assegurando a participação na sociedade, a segurança social e a solidariedade social para todos e encorajando o potencial de todas as gerações. Já em 17 de maio desse mesmo ano, o Parlamento Europeu e o Conselho decidem ${ }^{34}$ instituir 2007 como o "Ano Europeu da Igualdade de Oportunidades para Todos - Para uma Sociedade Justa", com o objetivo de intensificar os seus esforços para combater a discriminação em razão do sexo, raça ou origem étnica, religião ou crença, deficiência, idade ou orientação sexual.

O ano seguinte foi um ano profícuo, com duas Comunicações e dois Pareceres, ambos do Comitê Econômico e Social. A primeira Comunicação da Comissão nesse ano foi no dia 10 de maio, tendo como título "Promover a Solidariedade entre as Gerações",35, sobre a qual o Comitê Econômico Social emitiu Parecer, em 13 de dezembro de 2007, alertando sobre a profundidade e multidimensionalidade desta temática, que não deve ser restringida à questão demográfica, devendo "ser considerado, cada vez mais, como uma questão prioritária dos próximos anos, para os centros horizontais de responsabilidade (instituições, parceiros sociais, organizações da sociedade civil, etc.) e para os centros verticais (jovens, idosos, etc.), na medida em que são determinantes para o desenvolvimento europeu (económico, social e cultural) e para renovar o próprio pacto social pelo qual se regem as nossas democracias"36. Em 14 de

\footnotetext{
${ }^{33}$ Resolução do Parlamento Europeu sobre os desafios demográficos e a solidariedade entre gerações. Publicado no Jornal Oficial da União Europeia de 01/12/2006. Disponível em: http://eurlex.europa.eu/LexUriServ/LexUriServ.do?uri=OJ:C:2006:292E:0131:0140:PT:PDF, [Acesso em 14/01/2014].

${ }^{34}$ Decisão n ${ }^{\circ}$ 771/2006/CE do Parlamento Europeu e do Conselho, de 17 de Maio de 2006, publicada no Jornal Oficial da União Europeia de 31/05/2006. Disponível em:

http://eur-lex.europa.eu/LexUriServ/LexUriServ.do?uri=OJ:L:2006:146:0001:0007:PT:PDF, [Acesso em 14/01/2014].

${ }^{35}$ Disponível em:

http://eur-lex.europa.eu/LexUriServ/LexUriServ.do?uri=COM:2007:0244:FIN:PT:PDF, [Acesso em $14 / 01 / 2014]$.

36 "Parecer do Comité Económico e Social sobre a Comunicação da Comissão ao Conselho, ao Parlamento Europeu, ao Comité Económico e Social Europeu e ao Comité das Regiões - Promover a solidariedade entre as gerações". Publicado no "Jornal Oficial da União Europeia", 16/05/2008. Disponível em:

http://eur-lex.europa.eu/LexUriServ/LexUriServ.do?uri=OJ:C:2008:120:0066:0072:PT:PDF, [Acesso em: 14/01/2014].
} 
março, o Comitê Econômico e Social emitiu outro Parecer ${ }^{37}$, dessa vez, relativo ao impacto econômico e orçamental do envelhecimento, no qual conclui que o aumento da idade legal da reforma pressupõe necessariamente que se realizem esforços consideráveis nos domínios da saúde e da segurança no trabalho. A segunda Comunicação da Comissão, nesse ano, foi elaborada em 14 de junho e apresentava um "Plano de Ação no domínio das Tecnologias da Informação e das Comunicações e Envelhecimento", intitulado "Envelhecer bem na sociedade da informação"38.

Em 12 de março de 2008, o Parlamento Europeu edita uma Resolução relativa à melhoria da qualidade de vida das pessoas de idade através da utilização das novas tecnologias da informação e da comunicação (TIC) ${ }^{39}$. Em seguida, em 09 de julho de

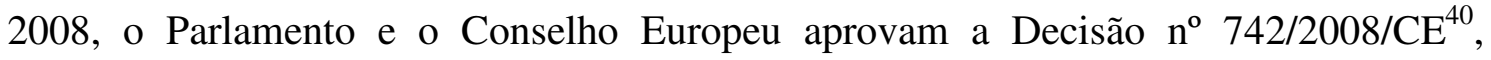
relativa a essa mesma matéria, onde estabelece diretrizes para um programa de investigação e desenvolvimento intitulado "Assistência à Autonomia no Domicílio". Nesse mesmo ano, o Comitê Econômico e Social emite Parecer ${ }^{41}$ sobre o tema "Ter em conta as necessidades dos mais velhos", onde, entre outras recomendações, sugere: a elaboração regular de relatórios sobre a situação a nível nacional e regional; a recolha e divulgação de exemplos de boas práticas nos Estados-Membros; a promoção de uma nova imagem do envelhecimento, que reconheça o contributo dado pelas pessoas mais velhas (incluindo os imigrantes) durante a sua vida e as virtudes da idade para a política, a economia e a sociedade; a organização de campanhas na comunicação social sobre "envelhecimento ativo".

Finalizando a década, em 2009 são protagonizados quatro atos legislativos sobre envelhecimento pela União Europeia. Em 03 de fevereiro, o Parlamento Europeu manifesta-se, através de uma Resolução, sobre a ausência de discriminação com base no

\footnotetext{
37 "Parecer do Comité Económico e Social sobre O impacto económico e orçamental do envelhecimento". Publicado no "Jornal Oficial da União Europeia" de 13/07/2007. Disponível em: http://eurlex.europa.eu/LexUriServ/LexUriServ.do?uri=OJ:C:2007:161:0001:0008:PT:PDF, [Acesso em: 14/01/2014].

${ }^{38}$ Disponível em:

http://eur-lex.europa.eu/LexUriServ/LexUriServ.do?uri=COM:2007:0332:FIN:PT:PDF, [Acesso em: $14 / 01 / 2014]$.

39 "Jornal Oficial da União Europeia", 20/03/2009. Disponível em: http://eurlex.europa.eu/LexUriServ/LexUriServ.do?uri=OJ:C:2009:066E:0128:0128:PT:PDF, [Acesso em 10/03/2014].

40 Publicado no "Jornal Oficial da União Europeia" em 30/07/2008. Disponível em: http://eurlex.europa.eu/LexUriServ/LexUriServ.do?uri=OJ:L:2008:201:0049:0057:PT:PDF, [Acesso em: $14 / 01 / 2014]$.

41 "Parecer do Comité Económico e Social sobre o tema Ter em conta as necessidades dos mais velhos". Publicado no "Jornal Oficial da União Europeia" de 31/03/2009. Disponível em: http://eurlex.europa.eu/LexUriServ/LexUriServ.do?uri=OJ:C:2009:077:0115:0122:PT:PDF, [Acesso em: 14/01/2014].
} 
sexo e a solidariedade entre gerações ${ }^{42}$. No mês seguinte, em 25 de março, o Comitê Econômico e Social emite Parecer sobre a "Situação dos Trabalhadores Mais Velhos Face às Mutações Industriais - Assegurar o apoio e gerir a diversificação da estrutura de idades nos sectores de actividade e nas empresas" ${ }^{\text {"43 }}$, onde propõe a gestão da diversidade como um dos métodos para focar o problema do emprego das pessoas mais velhas; em 29 de abril, a Comissão publica a Comunicação "Gerir o impacto do envelhecimento da população na UE (Relatório sobre o Envelhecimento Demográfico 2009)"44; e, em 12 de junho de 2009, o Parlamento publica Decisão ${ }^{45}$ relativa à interpretação dos artigos $50^{\circ}, n^{\circ} 4,58^{\circ}$ e $87^{\circ}, n^{\circ} 5$, do Regulamento (CE) n $n^{\circ} 883 / 2004$ do Parlamento Europeu e do Conselho para a concessão de prestações por invalidez, velhice e sobrevivência, clarificando a aplicação dos referidos artigos e fornecendo orientações para sua aplicação.

Na década seguinte, em 2010 foram emitidos dois Pareceres pelo Comitê Econômico e Social: um Parecer Exploratório sobre "As consequências do envelhecimento da população para os sistemas sociais e de saúde", emitido em 15 de julho e publicado pelo Jornal Oficial da União Europeia em fevereiro do ano seguinte ${ }^{46}$, e outro, emitido em 21 de outubro, sobre a proposta de decisão do Parlamento Europeu e do Conselho relativa ao Ano Europeu do Envelhecimento Activo (2012) ${ }^{47}$, cujo Parecer foi favorável, porém com a importante ressalva:

(...) No entanto, este título e o conceito que lhe está subjacente não reflectem o que, em sua opinião [do Comitê], deveria estar no centro desse Ano Europeu, ou seja, um envelhecimento activo, mas também com saúde, dignidade e alegria de viver. Assim, o

\footnotetext{
42 Publicada no "Jornal Oficial da União Europeia", 18/03/2010. Disponível em: http://eurlex.europa.eu/LexUriServ/LexUriServ.do?uri=OJ:C:2010:067E:0031:0037:PT:PDF, [Acesso em 04/03/2014].

${ }^{43}$ Publicado no "Jornal Oficial da União Europeia" em 22/09/2009. Disponível em: http://eur-lex.europa.eu/LexUriServ/LexUriServ.do?uri=OJ:C:2009:228:0024:0031:PT:PDF, [Acesso em: 14/01/2014].

${ }^{44}$ Disponível em:

http://eur-lex.europa.eu/LexUriServ/LexUriServ.do?uri=COM:2009:0180:FIN:PT:PDF, [Acesso em: $14 / 01 / 20149$.

${ }^{45}$ Publicada no "Jornal Oficial da União Europeia" em 24/04/2010. Disponível em: http://eur-lex.europa.eu/LexUriServ/LexUriServ.do?uri=OJ:C:2010:106:0021:0022:PT:PDF, [Acesso em: $14 / 01 / 2014]$.

${ }^{46}$ Disponível em:

http://eur-lex.europa.eu/LexUriServ/LexUriServ.do?uri=OJ:C:2011:044:0010:0016:PT:PDF, [Acesso em: 14/01/2014].

${ }^{47}$ Publicado no "Jornal Oficial da União Europeia" em 17/02/2011. Disponível em: http://eur-lex.europa.eu/LexUriServ/LexUriServ.do?uri=OJ:C:2011:051:0055:0058:PT:PDF, [Acesso
} em: $14 / 01 / 2014]$. 
"envelhecimento activo" não deve entender-se apenas como a possibilidade de prolongar a actividade profissional ou a participação na sociedade. Solicita-se, por isso, à Comissão que adopte um título menos restritivo que leve também em conta estes outros aspectos da qualidade de vida. (PARECER DO COMITÊ ECONÔMICO E SOCIAL SOBRE A PROPOSTA DE DECISÃO DO PARLAMENTO EUROPEU E DO CONSELHO RELATIVA AO ANO EUROPEU DO ENVELHECIMENTO ACTIVO (2012))

Ainda em 2010, em 14 de abril, o Comitê das Regiões emite Parecer sobre "Gerir o impacto do envelhecimento da população na UE (relatório sobre o envelhecimento demográfico de 2009)",48. Este Parecer defende uma abordagem orientada para as regiões a fim de enfrentar as consequências do envelhecimento demográfico nos seguintes temas: envelhecer com saúde; participação no mercado de trabalho e produtividade; e acesso aos serviços e aos equipamentos, além de associar-se à iniciativa de proclamar 2012 como o Ano do Envelhecimento Activo e Saudável e da Solidariedade entre Gerações, com a plena participação das crianças. Nesse mesmo ano, em 11 de novembro, é editada uma Resolução do Parlamento Europeu, acerca dos desafios demográficos e a solidariedade entre gerações ${ }^{49}$.

No ano seguinte, 11 em julho de 2011, a Comissão recomenda ${ }^{50}$, entre outras orientações, que os Estados-Membros cooperem com a Comissão no sentido de elaborarem e executarem a agenda de investigação estratégica e de coordenarem os programas conjuntos com outras iniciativas da União no domínio dos potenciais e desafios demográficos, tais como a Parceria Inovadora para o Envelhecimento Ativo e Saudável e o programa conjunto Assistência à Autonomia no Domicílio. No dia 07 de julho, o Parlamento edita uma Resolução sobre uma proposta de decisão do Parlamento

\footnotetext{
48 "Jornal Oficial da União Europeia", 27/08/2010. Disponível em: http://eurlex.europa.eu/LexUriServ/LexUriServ.do?uri=OJ:C:2010:232:0007:0013:PT:PDF. [Acesso em 10/03/2014].

49 Publicada no "Jornal Oficial da União Europeia", 13/03/2012. Disponível em: http://eurlex.europa.eu/LexUriServ/LexUriServ.do?uri=OJ:C:2012:074E:0019:0034:PT:PDF, [Acesso em: 04/03/2014].

50 "Recomendação da Comissão de 11 de Julho de 2011, relativa ao programa de investigação conjunto Viver mais tempo, viver melhor — O potencial e os desafios das alterações demográficas", publicado no "Jornal Oficial da União Europeia" em 13/07/2011 e disponível em: http://eur-lex.europa.eu/LexUriServ/LexUriServ.do?uri=OJ:L:2011:183:0028:0030:PT:PDF, [Acesso em: 14/01/2014].
} 
Europeu e do Conselho relativa ao Ano Europeu do Envelhecimento Activo (2012) ${ }^{51}$. Em 14 de setembro do mesmo ano, o Parlamento e Conselho decidiram instituir 2012 como o "Ano Europeu do Envelhecimento Ativo e da Solidariedade em Gerações" 52 .

Em 29 de fevereiro de 2012, a Comissão definia diretrizes para a concretização do "Plano de Execução Estratégica da Parceria Europeia de Inovação para um Envelhecimento Ativo e Saudável”, colocando como imprescindível a garantia de apoio nos níveis da UE, dos Estados-Membros, das regiões e das localidades, com vias a um envelhecimento ativo tanto "para melhorar a qualidade de vida dos cidadãos idosos e ajudá-los a participar ativamente na sociedade à medida que envelhecem, como para reduzir a pressão insustentável sobre os sistemas de saúde" ${ }^{, 53}$. Nesse ano, o Comitê Econômico e Social emitiu dois pareceres sobre a matéria: um, de 23 de maio, referente à análise sobre o "Horizonte 2020 - Roteiros para o envelhecimento", no qual recomenda investigações sobre "aspetos mais inovadores e, possivelmente, mais problemáticos do envelhecimento e das alterações demográficas", dos quais cita "a manutenção da saúde e a reabilitação, o prolongamento da vida ativa, as implicações de as pessoas cada vez mais tomarem e compartilharem a responsabilidade pelas suas vidas, a aprendizagem para uma maior longevidade, o impacto do papel crescente da técnica em diversos domínios da vida e as questões decorrentes das alterações demográficas, sociais e técnicas na sociedade europeia" ${ }^{\text {; }}$; e outro, de 14 de novembro, sobre "O contributo e a participação dos idosos na sociedade", onde realça que a idade cronológica é apenas uma das muitas características que definem uma pessoa e que uma sociedade inclusiva exige uma responsabilidade coletiva, "assumida pelos decisores políticos, pelas partes interessadas e pelos próprios cidadãos quando da definição de políticas e práticas que assegurem a equidade e a inclusão, independentemente da

\footnotetext{
${ }^{51}$ Resolução publicada no "Jornal Oficial da União Europeia” em 05/02/2013. Disponível em: http://eurlex.europa.eu/LexUriServ/LexUriServ.do?uri=OJ:C:2013:033E:0364:0365:PT:PDF, [Aceso em: $14 / 01 / 2014]$.

52 "Decisão no 940/2011/UE do Parlamento Europeu e do Conselho", publicada no "Jornal Oficial da União Europeia" em 23/09/2011. Disponível em:

http://eur-lex.europa.eu/LexUriServ/LexUriServ.do?uri=OJ:L:2011:246:0005:0010:PT:PDF, [Acesso em: 14/01/2014].

${ }^{53}$ Comunicação disponível em:

http://eur-lex.europa.eu/LexUriServ/LexUriServ.do?uri=COM:2012:0083:FIN:PT:PDF, [Acesso em: $14 / 01 / 2014]$.

54 "Parecer do Comité Económico e Social Europeu sobre o Horizonte 2020 - Roteiros para o envelhecimento" (parecer de iniciativa), publicado no "Jornal Oficial da União Europeia" em 31/07/2012. Disponível em: http://eur-lex.europa.eu/LexUriServ/LexUriServ.do?uri=OJ:C:2012:229:0013:0017:PT:PDF, [Acesso em: 16/01/2014].
} 
idade" 55 . Ainda em 2012, o Comitê das Regiões emite Parecer intitulado "Envelhecimento ativo: inovação - saúde inteligente - viver melhor",56

Finalmente, fechando a legislação comunitária sobre as questões relativas ao envelhecimento publicadas até então, em 17 de dezembro de 2013, o Parlamento e o Conselho publicam o Regulamento ${ }^{57}$ que cria o Programa "Direitos, Igualdade e Cidadania" para o período de 2014 a 2020, reforçando, mais uma vez, o compromisso da UE em viabilizar uma Europa sem discriminação e sem desigualdades sociais.

\section{Considerações Finais}

Ao término deste percurso, onde se propôs a realizar um levantamento sobre a legislação comunitária para o envelhecimento, algumas considerações podem ser tecidas.

Em primeiro lugar, observa-se que a atenção dos olhares da União Europeia para a questão do envelhecimento se deu, muito fortemente, em razão das novas configurações demográficas globais e, marcadamente, da Europa que vive, na contemporaneidade, um franco e constante envelhecimento populacional. A primeira preocupação se dá, assim, em termos econômicos e de sustentabilidade social.

Em um primeiro momento, os documentos comunitários, incluindo aí a Carta dos Direitos Fundamentais da União Europeia, parecem homogeneizar os idosos, tratando-os em oposição aos mais jovens. Os idosos passam, nessa visão, a ser considerados como os "outros" em relação a um padrão de normalidade, representado pelos mais jovens. Essa crítica é elaborada por Ivic (2013), que denuncia:

A Carta dos Direitos Fundamentais da UE considera a categoria "idosos" um grupo homogêneo à luz do enunciado contindo em seu Artigo 25 (Direito dos idosos). Contudo, o conceito de "idosos" inclui diferentes práticas narrativas, interesses e

\footnotetext{
55 "Parecer do Comité Económico e Social Europeu sobre O contributo e a participação dos idosos na sociedade" (parecer de iniciativa), publicado no "Jornal Oficial da União Europeia" em 15/01/2013. Disponível em:

http://eur-lex.europa.eu/LexUriServ/LexUriServ.do?uri=OJ:C:2013:011:0016:0020:PT:PDF, [Acesso em: $16 / 01 / 2014]$.

56 "Jornal Oficial da União Europeia", 27/07/2012. Disponível em: http://eurlex.europa.eu/LexUriServ/LexUriServ.do?uri=OJ:C:2012:225:0046:0051:PT:PDF, [Acesso em $10 / 03 / 2014]$.

57 "Regulamento (UE) no 1381/2013 do Parlamento Europeu e do Conselho, de 17 de dezembro de 2013". Publicado no "Jornal Oficial da União Europeia" em 28/12/2013 e disponível em: http://eurlex.europa.eu/LexUriServ/LexUriServ.do?uri=OJ:L:2013:354:0062:0072:PT:PDF, [Acesso em: $16 / 01 / 2014]$.
} 
experiências e deve ser considerado heterogêneo. O conceito inclui grupos diferentes de adultos mais velhos tais como: imigrantes, refugiados, idosos mental e fisicamente debilitados, etc. A ideia de adultos de mais idade apresentado na Carta dos Direitos Fundamentais da EU não leva em conta discriminações múltiplas sofridas por adultos idosos. (IVIC, 2013, p. 196).

Nessa mesma direção, encontram-se na legislação termos como "envelhecimento ativo", por exemplo, diretamente atrelados à vida ativa no mercado de trabalho. O idoso "não ativo", nessa perspectiva, representa o sujeito ocioso, que depende do fruto do trabalho alheio sem apresentar uma contrapartida. Cria-se, assim, com essa imagem, um movimento contrário ao da solidariedade entre gerações, proposta em vários textos da legislação, onde a palavra "solidariedade" parece muito mais um sinônimo de "caridade" (dos mais jovens em relação aos mais velhos), e não um processo relacional.

Ao caminharmos pelos atos legislativos comunitários, avançando cronologicamente, entretanto, podemos perceber uma tentativa de mudança de certos paradigmas: a velhice começa a ser representada não como um obstáculo ao desenvolvimento, mas como uma parcela da população que pode contribuir em vários aspectos culturais e sociais. Questões como as mencionadas acima começam a ser levantadas através dos pareceres, demonstrando que as comissões e comitês vão, ao longo desse processo, construindo um conhecimento mais amplo e aprofundado sobre temática do envelhecimento, muito provavelmente alimentados pelas investigações incentivadas pela própria UE.

Dessa forma, um ponto importante parece aflorar. Se passarmos um rápido olhar sobre os atos legislativos comunitários sobre o envelhecimento, podemos perceber que os atos com poder decisório e com obrigatoriedade legal são poucos, no cômputo geral. Os pareceres, recomendações e comunicações são documentos muito mais frequentes do que os regulamentos, diretivas ou decisões. Numa primeira análise, esta constatação pode ser tomada como uma falta de políticas comunitárias específicas para a velhice. Por outro lado, no entanto, é preciso perceber a necessidade de um debate exaustivo requerido pelas questões de cunho social e cultural, principalmente dentro de uma comunidade que, não obstante a busca por certa unidade, apresenta inevitáveis diferenças.

Outro realce deve ser dado ao esforço comunitário, no decorrer dos anos, em debater as questões do envelhecimento sob diversas dimensões. Assim, o 
envelhecimento começa a ser visto não só pela ótica da saúde, mas, também, pelos prismas social e cultural, que passam a se configurarem como umas das maiores preocupações nos argumentos dos pareceristas comunitários.

O espírito humanista e democrático da União Europeia, fortemente transparecido no Tratado de Lisboa, que consagrou "solenemente a matriz de valores fundacionais: dignidade humana, liberdade, solidariedade, promoção da Paz, paridade, democracia, justiça, entre outros, valores estes que são simultaneamente universais e marco da identidade europeia" (VALENTE, 2012, p. 72), parece ir se fortalecendo ao longo do proceso de construção da legislação comunitária sobre o envelhecimento.

É certo que há muito por avançar. A ideia de uma "velhice produtiva" perpassa, ainda, o texto legislativo comunitário. A solidariedade ainda parece uma via de mão única, em que os mais jovens dão e os mais velhos recebem. A categoria homogeneizante de "idoso", ou de "pessoas de mais idade", ou, ainda, os "mais velhos" permanece, simplificando o envelhecimento como fator prioritariamente etário e desqualificando as pessoas enquanto sujeitos únicos. Entretanto, a produtividade passa a ser questionada em nome de outros valores, como a dignidade e a alegria de viver; uma solidariedade real, entre sujeitos em pé de igualdade, mas com diferentes contribuições a oferecer e a receber passa a ser estimulada em novas discussões; e a categoria de "idoso" passa a ser complexificada e questionada.

Caminhar pela legislação comunitária para o envelhecimento não é, pois, passear por um jardim florido, completo e acabado. É, antes de tudo, enveredar-se por caminhos ainda a serem construídos.

As análises e investigações sobre o envelhecimento devem, cada vez mais, ser aprofundadas, priorizando a complexidade das relações humanas, sociais e culturais.

\section{Fontes e Bibliografia:}

\section{Fontes:}

Sítios da Internet:

http://eur-lex.europa.eu/pt/index.htm, [Último acesso: 16/01/2014]. http://europa.eu/pol/index_en.htm, [Último acesso: 10/01/2014]. http://eur-lex.europa.eu/JOIndex.do?ihmlang=pt, [Último acesso: 16/01/2014]. http://undesadspd.org/Ageing.aspx, [Último acesso: 09/01/2014]. http://europa.eu/about-eu/countries/index_pt.htm, [Último acesso: 13/01/2014]. 


\section{Bibliografia:}

GASPAR, Jorge. "O Envelhecimento e a Dinâmica Demográfica na Europa Posicionando Portugal". In: O Tempo da Vida - Fórum Gulbenkian de Saúde sobre o Envelhecimento 2008/2009. Cascais: Princípia, 2009, ISBN 978-989-8131-56-0. p. 5076.

INVIC, Sanja. "O Direito dos Idosos na União Europeia”. In: DADOS - Revista das Ciências Sociais, Rio de Janeiro, vol. 56, nº 1, 2013, ISSN 1678-4588. p. 185-205.

VALENTE, Isabel Maria Freitas. "A Europa dos Cidadãos: reflexões sobre a Carta dos Direitos Fundamentais e a Iniciativa de Cidadania Europeia". In: Debater a Europa Periódico do CIEDA e do CEIS20, em parceria com GPE e a RCE. $n^{\mathbf{0}}$ 7, Julho/Dezembro $2012 \quad$ - semestral. ISSN 1647-6336. Disponível em: http://www.europe-direct-aveiro.aeva.eu/debatereuropa/, [Acesso: 14/01/14].

WILSON, Chris. "O Envelhecimento no Séc. XXI - Perspectivas Demográficas”. In: O Tempo da Vida - Fórum Gulbenkian de Saúde sobre o Envelhecimento 2008/2009. Cascais: Princípia, 2009, ISBN 978-989-8131-56-0. p. 40-49.

Livro:

SILVA, António Martins da. História da Unificação Europeia - A Integração Comunitária (1945-2010). Coimbra: Imprensa da Universidade de Coimbra, 2010, 374 p. ISBN 978-989-26-0057-4. 